\title{
Study on the Setup of College English Follow-up Course in Application-oriented University Based on the Needs Analysis
}

\author{
Ju Changzhen ${ }^{1}$ \\ ${ }^{1}$ Wuhan Donghu University, Wuhan, Hubei, 430000
}

Keywords: setup; College English; follow-up courses; needs analysis

\begin{abstract}
Applied colleges and universities pay more attention to their English practice and study. This paper mainly studies the objectives of College English follow-up courses through questionnaires, and studies the types of courses and the needs of teaching content. By means of questionnaires, the students' needs to learn English courses and their desire to learn English and relevant curriculum knowledge are analyzed. Through the survey, it is found that more students are more interested in the self-learning model and hope to improve self-learning through online teaching. The establishment of College English follow-up courses considers teachers as a basis for face-to-face teaching to improve the course objectives of College English and meet the needs of society for applied talents, which requires that College English teachers pay attention to continuous improvement in teaching philosophy, further improve the content of teaching through knowledge, create new teaching concepts and teaching methods, and at the same time strengthen communication with students, strengthen the improvement of knowledge structure, innovate teaching methods, and stimulate students' interest and enthusiasm in learning English to improve teaching quality of College English.
\end{abstract}

\section{Introduction}

The students of applied colleges and universities are very urgently needed by employers. Among such employers, the students of universities and colleges urgently carry out many aspects of learning to enhance their abilities. The first is the requirement for listening skills, which requires the learning of professional courses for listening training; the second is that the employer is the unit mainly needs to have certain communication skills to serve the work, and for such needs, the applied colleges and universities propose the follow-up course of college English.[1]According to the student's level, we will use different levels of teaching and teaching, set up courses suitable for employers, and improve students' learning. The establishment of such follow-up courses is very necessary, because in the teaching of English courses, there is no ready-to-use teaching model to follow, and how to set application-oriented college English follow-up courses has become an immediate problem to be solved.

\section{Research Background of College English Follow-up Courses}

In order to promote reform of college English teaching, continuously improve the level of college English teaching, and cultivate students' comprehensive ability in English application, the Ministry of Education organizes relevant experts to formulate the "Requirements for College English Course Teaching” (2004) [1]. College English teaching is an integral part of higher education is a compulsory basic course for undergraduates. It is based on English language knowledge and application skills, learning strategies and cross-cultural communication. It is guided by foreign language teaching theory and incorporates a variety of teaching modes and teaching methods. In 2007, the "University English Course Teaching Requirements" was formally promulgated. In terms of curriculum setting, according to the actual situation of colleges and universities, and the English teaching conditions of various universities, English course objectives and language skills were integrated to make different English-based In the process of learning English, students are fully trained in language and ability. Combining major courses with elective 
courses will ensure that students from different levels will improve their English skills. [2] In 2010, the "Summary of College English Informatization Teaching Reform Achievements and Foreign Languages General Education and Curriculum Setting High Level Forum" was held at Sun Yat-sen University. It was very important to present the follow-up course of College English and it was necessary to train students to improve their quality [3]. Comprehensive ability to increase the planning of follow-up courses. The teaching objectives of the school should be based on the method of teaching students in accordance with their aptitude and teaching according to the student's level. Before 2010, many scholars who studied college English still had a superficial understanding of the understanding of the college English curriculum system. They did not have a good research effect on establishing the curriculum system and the curriculum content. College English in applied universities needs further innovation and optimization. In most of them, audio-visual English courses are set up, and the main teaching models are adapted to the needs of social talents. Students need to meet their own needs through study and better access. Society, serves the society. The reform of college English has presented a fact of deepening development. Many colleges and universities have lagging behind in the teaching mode of comprehensive English and English listening and speaking. Because the learning of college students can not only stay on the basis of audiovisual, it needs to be based on the students themselves. Requests for the establishment of learning courses. The follow-up course construction should not only improve the students' level of learning, but also be conducive to the professionalization of students in order to meet the development needs of their respective professions. With the continuous development of colleges and universities, English teaching has set up follow-up courses, constructed a multi-faceted teaching curriculum, integrated diversified education methods, optimized the setting of courses, and satisfied the desires and requirements of different students.

\section{Research of College English Follow-up Courses}

\subsection{Analysis of student needs}

The West believes that the so-called needs analysis is mainly a way and strategy for conducting research through the form of observations and questionnaires. In foreign countries, the analysis of needs and needs was in the 1980s. Linguists used different perspectives to analyze and define their needs. This linguistics has also established an analytical model as an analysis of the language of social relations. [3] Of course, some scholars in China have also made some research. The demand analysis believes that both social needs and individual needs are a kind of demand. The analysis of individual needs and social needs, the construction of the model and the theory of college English needs from different perspectives, the concept of needs analysis into the English class in colleges and universities, the needs of students have been designed to become a choice in the curriculum Part. While investigating the universities in our country, we found that more than average students have certain requirements for learning English, and they mainly require teaching contents and teaching courses. Most of the scholars only stayed in the study of English learning courses in institutions of higher learning, and did not propose practical solutions for the setting of follow-up courses in English.

\subsection{Research on the curriculum setup}

With the development of teaching, curriculum teaching has become a concern for people. Scholars in our country believe that the course refers to a system of teaching activities, and that the purpose of school education is to focus on the educational activities of the discipline. On the basis of the choice of construction, it is necessary to cultivate targeted goals and form a certain understanding through association. In the course of curriculum setting, it is necessary to select and plan courses according to different students, learning contents, social needs, etc., and then to plan these organizations for a process of arrangement. The setting of this process is based on language and skills, combined with the acquisition of certain knowledge in English. Such knowledge is comprehensive and practical. In the college English teaching system, General English and 
Professional English are used to classify these courses. Through research, it is found that language is a practical tool. Therefore, College English is transformed from the language knowledge skills. In the process of transformation, English is used as a carrier to transmit information, and professional communication methods are provided through external communication and cooperation. How to adapt the English course to the development of applied talents and enhance the students' ability to enhance the application of English communication is a problem that college English teaching needs to pay attention to.

\section{Investigation and Analysis of College English Follow-up Courses}

\subsection{Questionnaire survey}

This paper analyzes the follow-up courses of university courses in colleges and universities through questionnaires. The need for students' English follow-up courses can be achieved through the college students' English examination status and the need to organize survey questionnaires, focusing on students' needs. Questionnaires for 15th and 16th grade students of the school were applied to students' post-study courses. (Table 1) Questionnaire surveys were conducted for liberal arts and science and engineering subjects. This survey was more baseful and passed questionnaire surveys. Can cover the needs of the entire student. In the questionnaire survey, targeted and targeted interviews were conducted for students in order to obtain more information and make the information more real and effective. In the questionnaire survey, the principle of bearer name was selected. According to the results of the data, it was found that 100 questionnaires were passed. The investigation will be resumed, including the need for English learning, the idea of follow-up courses, investigation and analysis through follow-up course teaching content and objectives, etc., which can provide certain reference for the follow-up course setting of application-oriented colleges and universities.

Table 1 Basic information of students surveyed

\begin{tabular}{|l|l|l|l|}
\hline \multirow{3}{*}{ Gender } & Male & 52 & $52 \%$ \\
\cline { 2 - 4 } & Female & 48 & $48 \%$ \\
\hline \multirow{3}{*}{ Professional } & Arts & 46 & $46 \%$ \\
\cline { 2 - 4 } & Science & 54 & $54 \%$ \\
\hline Total & 100 & \multicolumn{2}{|l}{} \\
\hline
\end{tabular}

\subsection{Conclusion}

According to the survey results, the students strongly hope to follow their own needs through follow-up courses, because the content of the course content of the corresponding test is different. During the investigation of the English follow-up course, it is found that many university students have to work because of the pressure of employment. There is a growing number of students who have increased their English proficiency in their professional English and have increased their English language ability through English grading. [4] Many students learn professional knowledge and go to master bloggers to increase their employment competitiveness. Although the current college English teaching pays attention to the cultivation of applied talents, it cannot measure the English level of students effectively, and can only be evaluated by the way of grading. Many employers, especially those who pay attention to applied talents, will also use the grading certificate as an employer's reference standard. Therefore, students' learning is mainly due to the needs of the society and the pressure of employment. With the investigation of English courses, students found that they have their own requirements for compulsory courses, they also have their own opinions on elective courses, and they have a strong reaction in the appreciation of foreign films and the study of British and American cultures. This shows that the development of society adapts to the development of applied models. Talent. The exchanges between China and the international community are increasingly frequent. More and more students hope to learn more about the culture of many countries through language learning, broaden their horizons, and enhance their 
communication skills [8].

\section{Exploration of College English Follow-up Courses in Application-oriented Universities}

\subsection{Build a diversified teaching system}

The continuous improvement of the teaching system is mainly accomplished through improving the quality of teaching. In the colleges and universities to carry out the demand analysis theory exploration, the university student needs analysis as a whole module, through the questionnaire survey students need to carry out the English course needs analysis, through the survey found that the existence of the status and inadequacies in English teaching. The information, under the guidance of English teaching, will summarize and plan new forms, start from individuals, design diversified courses, meet students' learning needs, teach students in accordance with their aptitude, and expand the range of teaching courses through the needs of students. [5] The basic teaching and developmental teaching will be complementary to each other throughout the teaching. Through the survey, it is found that the setting of university courses can not meet the individual needs of the students, and the follow-up courses carried out to make up for the needs of students' employment. College students believe that English follow-up learning is more practical. They can improve the ability to apply English through the follow-up courses, and act on the actual work by cultivating language audiovisual aspects. It not only achieves the unity of the entire study course, but also runs through the teaching thinking. The establishment of this follow-up course lays the foundation for the students to reach the society.

\subsection{Implement follow-up courses in teaching}

Follow-up courses teaching is an important task for teachers to reform English courses. According to the needs of students, they can carry out teaching in different levels, diversify the teaching curriculum, and can carry out group teaching according to the needs of grades and classes, diversify the forms of teaching, and can conduct centralized guidance through the appreciation and debate of foreign fine works. With the help of electronic information technology, English is used to expand and exchange, and dialogues in the network are shared and exchanged to achieve students' interaction. Because students are not very strong in learning, it is difficult to improve the English level by relying solely on the Internet for independent learning. The advantages of the web platform combine mahjong classroom teaching with self-directed learning to improve the level of English learning. [6]

\subsection{Strengthen the construction of teachers}

In the process of college teachers' development of teaching, college English teaching through a certain optimization and innovation, the gradual combination of English classroom learning and follow-up courses in English to improve the English teaching model in colleges and universities to meet the needs of the community for applied talents. Students' development in the direction of diversification has become the overall needs of society and the students' demands. This requires the English teachers in universities to deepen the teaching content, improve the teaching methods, and sort out the knowledge structure. Under the environment of college education, the guiding role of teachers can not be ignored [9]. In the process of guiding, the concept of education should be transformed to improve their own level of knowledge and teaching ability. Therefore, the teacher's career planning systematization will be teacher education. Perfecting teaching is the key to the development of English curriculum. Efforts are made to improve the teaching level of college teachers, encourage teachers in various aspects, encourage teachers to actively promote their professional titles, and create diverse opportunities for teachers to participate in further education and teaching seminars. Improve their professional qualities and encourage teachers to actively set up follow-up courses. Strengthen the overall strength of the teacher team [10]. 


\section{Conclusion}

With the needs for applied talents in the society, the college English education continues to reform and develop. At present, English courses in colleges and universities are facing unprecedented challenges. With the rapid development of modern information technology, college English presents a diversified development direction from society. Starting from the individual, social needs as a guide, the use of flexible teaching methods, and gradually improve after-school courses to meet the requirements of college students.

\section{References}

[1] Yan Ting. Academic English: An Analysis of College English Follow-up Courses[J]. Cultural and Educational Resources, 2017(22):149-151.

[2] Li Xuwei. Research on the student's needs in English follow-up course setting in Baoding University from the perspective of ESP[J]. Education Education Forum, 2017(20):73-74.

[3] Zhou Shuang, Cheng He. The idea of college English follow-up courses based on demand analysis theory [J]. Journal of Jilin Institute of Business and Technology, 2017, 33(02): 120-122.

[4] Wang Lu, Wu Ling. Research on follow-up course setting of college English in independent college based on demand analysis[J]. Journal of Leshan Teachers College, 2017, 32(03):121-125.

[5] Wu Yue. A Study on the Satisfaction Degree of College English Follow-up Course Based on Student Demand Analysis [D]. Nanjing University of Aeronautics and Astronautics, 2017.

[6] Liu Xuanzhu. College English Teaching Reform - A Preliminary Exploration of Follow-up Courses [J]. Reading and Writing (educational journal), 2016, 13(05):13.

[7] Tian Ying. Research on College English follow-up course setting based on demand analysis [J]. Overseas English, 2015(23): 4-5+8.

[8] Zhang Hao, Wang Dan, Zhang Lijie. The setting and promotion strategy of college English follow-up course [J]. Overseas English, 2016(03):5-7.

[9] Yu Hui. Research on follow-up course setting of academic English and college English [J]. College English (Academic Edition), 2015, 12(02):35-39.

[10] Ren Jiadi. Research on college English follow-up course setting based on student needs analysis [D]. Xi'an International Studies University, 2015. 